\title{
Anion exchange membranes based on long side-chain quaternary ammonium-functionalized poly(arylene piperidinium)s for vanadium redox flow batteries
}

\author{
Xuefu Che ${ }^{1 \dagger}$, Weiqin Tang ${ }^{1 \dagger}$, Jianhao Dong ${ }^{1}$, David Aili ${ }^{2^{*}}$ and Jingshuai Yang ${ }^{{ }^{*}}$
}

\begin{abstract}
A new series of poly(arylene piperidinium)based anion exchange membranes (AEMs) are proposed for vanadium redox flow batteries (VRFBs). The AEMs are fabricated via the Menshutkin reaction between poly(arylene piperidine) without ether bonds in the backbone and various quaternizing agents, including iodomethane, 1-bromopentane, and (5-bromopentyl)-trimethylammonium bromide. The properties of the AEMs are investigated in terms of sulfuric acid doping content, swelling, vanadium permeability, ion selectivity, area-specific resistance, mechanical properties, VRFB performance, and cyclic testing. Particularly, a method of measuring the $\mathrm{H}^{+}$permeability of the AEM is developed. It demonstrates that the poly( $p$-terphenyl $-N$-methylpiperidine)quaternary ammonium (PTP-QA) membrane with a QA cation-tethered alkyl chain exhibits high $\mathrm{H}^{+}$permeability, resulting in low area resistance. Combined with its low vanadium permeance, the PTP-QA membrane achieves nearly 370 times higher ion selectivity than Nafion 115. The VRFB based on PTP-QA-based AEM displays high Coulombic efficiencies above $99 \%$ at current densities of $80-160 \mathrm{~mA} \mathrm{~cm}^{-2}$. The higher energy efficiency of $89.8 \%$ is achieved at $100 \mathrm{~mA} \mathrm{~cm}^{-2}$ (vs. $73.6 \%$ for Nafion 115). Meanwhile, the PTPQA-based AEM shows good cycling stability and capacity retention, proving great potential as the ion exchange membrane for VRFB applications.
\end{abstract}

Keywords: vanadium redox flow battery, anion exchange membrane, poly(arylene piperidinium), quaternary ammonium, $\mathrm{H}^{+}$permeability

\section{INTRODUCTION}

The increasing share of intermittent renewable energy based on solar and wind presents new challenges with respect to electric grid leveling and storage of energy [1]. Recently, vanadium redox flow batteries (VRFBs) have attracted enormous attention for potential large-scale energy storage devices due to advantages such as long cycle life, high battery performance, and large capacity [2-4]. The ion exchange membrane (IEM) has been regarded as the key component of VRFBs, which has the function of supporting ion conductivity while preventing the cross- mixing of redox-active species. The ideal IEMs for VRFBs should combine low vanadium ion permeability (to minimize self-discharging and capacity fading for high Coulombic efficiency $(\mathrm{CE}, \%)$ ), low area resistance (to support the conduction of charge-carrying ions and minimize ohmic polarization for high voltage efficiency (VE, \%)), high chemical and mechanical stabilities for superior cycle stability, and low manufacturing cost for large-scale commercial applications [3-7].

Over the past decades, cation exchange membranes (CEMs) have been extensively studied for VRFBs; a typical example is commercial Nafion because of its excellent chemical stability and superior conductivity [3,8-12]. However, the high price and high vanadium crossover of Nafion-type CEMs are major barriers to the development of VRFBs $[3,11]$. As a low-cost alternative, sulfonated poly(arylene ether) membrane chemistries have been explored for VRFBs [13-15]. Nevertheless, those membranes still suffer from the serious crossover of cationic vanadium species at high degrees of sulfonation, which is required to obtain high conductivity. This challenge mainly results from the intrinsic affinity of CEMs for cationic species, which facilitate crossover of cationic vanadium ions along with charge carries (i.e., protons), and research in this area has focused on balancing the desired proton conductivity versus the undesired migration and diffusion of cationic vanadium species $[8,16,17]$. Moreover, another challenge is the chemical stability of sulfonated poly(arylene ether)-type CEMs since the arylene ether bonds are prone to degrading in acidic environments due to the attack of vanadium oxygen species. This degradation mechanism is further promoted by the sulfonic acid groups attached to the backbone since the strong electron-withdrawing effect inductively increases the electrophilicity at the arylene ether link $[14,18]$.

Recently, anion exchange membranes (AEMs) based on quaternary ammonium (QA)-grafted polymers (including polysulfone [19-21], poly(arylene ether sulfone) [22-25], poly(arylene ether ketone) [26,27], cardo-polyetherketone [28], poly(fluorenyl ether) (PFE) [29-31] and poly(arylene ether benzonitrile) [32]) and imidazolium-functionalized polymers (such as poly(vinylimidazole) [33,34], poly(phenylene oxide) [35-37] and poly(arylene ether ketone) [38]) have been adopted for VRFB applications. Like sulfonated poly(arylene ether)-type

\footnotetext{
${ }^{1}$ Department of Chemistry, College of Sciences, Northeastern University, Shenyang 110819, China

2 Department of Energy Conversion and Storage, Technical University of Denmark, Elektrovej, Building 375, 2800 Lyngby, Denmark

$\dagger$ These authors contributed equally to this work.

* Corresponding authors (emails: larda@dtu.dk (Aili D); yjs@mail.neu.edu.cn (Yang J))
} 
membranes, most AEMs are derived from hydrocarbon-based backbones, which are relatively cheap compared with Nafion. One of the greatest advantages of AEMs for VRFBs is their significantly reduced vanadium ion permeability because of electrostatic repulsion between the fixed cationic groups of the membranes and the cationic vanadium ions. Thus, AEMs are believed to be permeable to anionic charge carriers (e.g., $\mathrm{HSO}_{4}{ }^{-}$ and $\mathrm{SO}_{4}{ }^{2-}$ ) and meanwhile effectively suppress cationic vanadium ions $[5,6,39]$. Consequently, it is reported that VRFBs based on a QA-grafted PFE-based AEM displayed a CE of nearly $100 \%$ [29]. Despite desired advantages of AEMs in terms of low cost and vanadium permeability, such membranes still face several challenges. One of them is chemical stability. It is reported that QA-grafted poly(arylene ether)-type AEMs are prone to degradation due to the attack of $\mathrm{VO}_{2}{ }^{+}$ions, resulting in oxidation to quinones $[19,40]$. Moreover, the intrinsic conductivity of AEMs is lower than that of CEMs (in pure water), which primarily results from the low intrinsic mobility of sulfate charge carriers (i.e., $\mathrm{HSO}_{4}{ }^{-}$and $\mathrm{SO}_{4}{ }^{2-}$ ) in the polymer matrix and aqueous electrolyte solution compared with $\mathrm{H}^{+}$mobility $[41,42]$. For example, the mobility of $\mathrm{SO}_{4}{ }^{2-}$ in an infinitely dilute solution at room temperature (RT) is $8.27 \times 10^{-8} \mathrm{~m}^{2} \mathrm{~V}^{-1} \mathrm{~s}^{-1}$, which is nearly one-fourth of the value of $\mathrm{H}^{+}$(i.e., $36.30 \times 10^{-8} \mathrm{~m}^{2} \mathrm{~V}^{-1} \mathrm{~s}^{-1}$ ) [43]. Therefore, developing new AEMs with low cost, low area-specific resistance (ASR), and suitable chemical and mechanical stabilities for VRFBs is still challenging.

Recently, AEMs based on polymers without ether bonds in the main chain have attracted increasing attention in the AEM fuel cell [44], water electrolysis [45], and VRFB [46] communities. For example, similar to Lee et al. [47], we have explored QAgrafted side-chain groups into polybenzimidazole (PBI) backbone (e.g., PBI-42\% EPTMA) by adopting 2,3-epoxypropyltrimethylammonium chloride (EPTMA-Cl) as the grafting agent via the $\mathrm{N}$-substitution reaction [48]. The obtained membranes displayed low vanadium permeability and enhanced VRFB efficiencies. More recently, a new class of terphenyl-based polymeric AEMs without arylene ether bonds were synthesized via a superacid-catalyzed reaction and applied in fuel cells [4952]. Results showed that this membrane family exhibited high anion conductivity, superior alkaline stability, and improved fuel cell performance [50,51]. However, only a few reports on terphenyl-based AEMs for VRFBs are available in the literature, as recently published by Wang et al. [53] and Yan et al. [54]. This inspired us to explore terphenyl-based AEMs in the context of VRFBs, with the ambition to suppress the vanadium crossover and capacity fade.

In this study, poly( $p$-terphenyl- $N$-methylpiperidine) (PTP) was synthesized by the polycondensation of $N$-methyl-4-piperidone and terphenyl via a superelectrophilic activation reaction in triflic acid. AEMs were subsequently fabricated via the Menshutkin reaction with iodomethane, 1-bromopentane, and (5-bromopentyl)-trimethylammonium bromide, respectively, to study the effect of side-chain groups on the AEM properties. The properties of the obtained AEMs were studied systematically relative to Nafion 115 as the reference membrane [55] from the aspects of sulfuric acid (SA) doping, swelling, surface resistance, mechanical properties, vanadium permeability, VRFB battery performance, and cyclic testing. Importantly, the $\mathrm{H}^{+}$permeability of AEMs was also determined to investigate the $\mathrm{H}^{+}$ migration of AEMs.

\section{EXPERIMENTAL SECTION}

\section{Synthesis of PTP}

PTP polymer was synthesized via superelectrophilic activation in trifluoromethanesulfonic acid (TFSA) [49,56]. In detail, p-terphenyl $(14.9 \mathrm{~g}, 64.6 \mathrm{mmol})$ was dissolved in dichloromethane $\left(\mathrm{CH}_{2} \mathrm{Cl}_{2}, \quad 24 \mathrm{~mL}\right)$; then, $N$-methyl-4-piperidone $(9.2 \mathrm{~mL}$, $78.8 \mathrm{mmol}$ ) was added. Trifluoroacetic acid (TFA, $5.3 \mathrm{~mL}$ ) was added, followed by dropwise addition of TFSA $(70 \mathrm{~mL})$ to the ice-batch cooled mixture during mechanical agitation. After stirring in an ice bath for about $3 \mathrm{~h}$, the viscous solution was poured into $1 \mathrm{~mol} \mathrm{~L}^{-1} \mathrm{NaHCO}_{3}$ (aq., $1.5 \mathrm{~L}$ ) to obtain a whitishyellow precipitate. The PTP polymer was shredded and washed thoroughly using deionized water until neutral, followed by drying in a vacuum oven at $120^{\circ} \mathrm{C}$ for $24 \mathrm{~h}$.

\section{Quaternization of PTP and fabrication of membranes}

PTP was quaternized with iodomethane, bromopentane, and (5bromopentyl)-trimethylammonium bromide (BPTMA-Br) via the Menshutkin reaction to form cationic poly $(p$-terphenyl piperidinium)s (hereafter referred to as PTP-Q $x$, i.e., PTP-Q1, PTP-Q5, and PTP-QA, respectively, Fig. 1). As a representative example, PTP-QA was prepared by first adding BPTMA-Br into a mixed solution of dimethyl sulfoxide (DMSO) and $\mathrm{N}$-methyl-2pyrrolidone (NMP) with a volume ratio of 1:3 under intense stirring. After BPTMA-Br was dissolved in the above mixed solution, the solid PTP was added proportionately with the above mixture. A homogeneous orange solution was obtained after stirring at $80^{\circ} \mathrm{C}$ for $12 \mathrm{~h}$. The PTP-QA polymer was precipitated by pouring the solution into diethyl ether, followed by washing, filtration, and drying. Through a similar procedure, PTP-Q1 and PTP-Q5 were produced. For further membrane fabrication processing, the three poly( $p$-terphenyl piperidinium)s were dissolved in DMSO at $80^{\circ} \mathrm{C}$ to form $3 \mathrm{wt} \%$ solutions. The polymer solutions were poured into Petri dishes, and the membranes were cast in an oven at $80^{\circ} \mathrm{C}$ for $24 \mathrm{~h}$. The membranes were delaminated in demineralized water, washed repeatedly with demineralized water, and further dried at $80^{\circ} \mathrm{C}$ for $24 \mathrm{~h}$, yielding transparent and flexible yellow-brownish AEMs (Fig. 1).

\section{SA doping and swellings}

The SA doping of PTP-Q $x$ membranes was performed by equilibrating the dry membranes in $3 \mathrm{~mol} \mathrm{~L}^{-1} \mathrm{SA}$ solution at RT for two days $[48,57,58]$. The acid-doped membranes were dried in a vacuum oven at $80^{\circ} \mathrm{C}$ for $24 \mathrm{~h}$. The acid doping content (ADC, \%) was defined as the mass fraction of SA per gram of the sample and calculated according to Equation (1), where $m_{1}$ and $m_{2}$ are the weight before and after SA doping, respectively. Accordingly, the volume swelling (VS, \%) of each membrane was calculated based on the volume change after submersing membranes in $3 \mathrm{~mol} \mathrm{~L}^{-1} \mathrm{SA}$ solution according to Equation (2), where $L, W$, and $T$ are the length, width, and thickness of the dry (1) and doped (2) membranes, respectively.

$$
\begin{aligned}
& \operatorname{ADC}(\%)=\frac{\left(m_{2}-m_{1}\right)}{m_{1}} \times 100 \%, \\
& \mathrm{VS}(\%)=\frac{L_{2} \times W_{2} \times T_{2}-L_{1} \times W_{1} \times T_{1}}{L_{1} \times W_{1} \times T_{1}} \times 100 \% .
\end{aligned}
$$

\section{Characterizations}

The physicochemical characterizations and properties of the ${ }^{1} \mathrm{H}$ nuclear magnetic resonance (NMR) spectrum, tensile properties, 

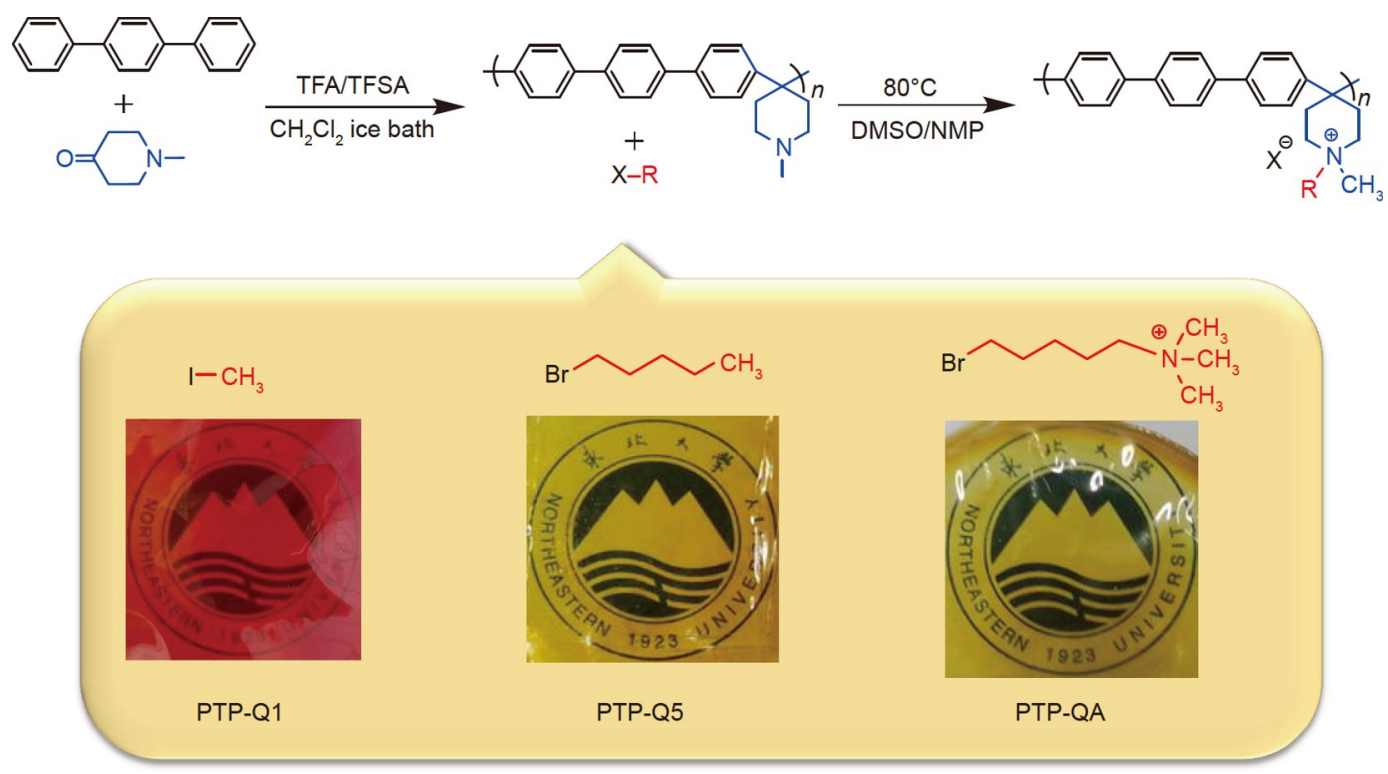

Figure 1 Synthesis of PTP and subsequent quaternization with alkyl halides.

ASR, and $\mathrm{VO}^{2+}$ permeability of membranes were determined as reported previously [47,59], and the experimental details are given in the Supplementary information.

The $\mathrm{H}^{+}$permeability of membranes was determined using the same device used for the $\mathrm{VO}^{2+}$ ion permeability measurement. However, the right cell was filled with $3 \mathrm{~mol} \mathrm{~L}^{-1} \mathrm{H}_{2} \mathrm{SO}_{4}$ solution, and the left one was filled with $3 \mathrm{~mol} \mathrm{~L}^{-1}\left(\mathrm{NH}_{4}\right)_{2} \mathrm{SO}_{4}$ solution to eliminate the osmotic pressure difference. The concentration of $\mathrm{H}^{+}$ion was measured by a $\mathrm{pH}$ meter at a regular time interval.

\section{VRFB performance and cycling durability}

The VRFB was assembled and measured according to our previous work $[48,59]$. The $\mathrm{CE}$, energy efficiency (EE, \%), and VE of the cell were calculated according to Equations (3-5), respectively, where $I$ is the current, $V$ is the voltage, and $t$ is the time, and subscripts $d$ and $c$ mean the discharge and charge process, respectively.

$$
\begin{aligned}
& \mathrm{CE}(\%)=\frac{\int I_{\mathrm{d}} \mathrm{d} t}{\int I_{\mathrm{c}} \mathrm{d} t} \times 100 \%, \\
& \mathrm{EE}(\%)=\frac{\int V_{\mathrm{d}} I_{\mathrm{d}} \mathrm{d} t}{\int V_{\mathrm{c}} I_{\mathrm{c}} \mathrm{d} t} \times 100 \%, \\
& \mathrm{VE}(\%)=\frac{\mathrm{EE}}{\mathrm{CE}} \times 100 \% .
\end{aligned}
$$

\section{RESULTS AND DISCUSSION}

\section{Polymer synthesis and AEM preparation}

As shown in Fig. 1, the PTP polymer was synthesized via the Friedel-Craft-type reaction between $\mathrm{N}$-methyl-4-piperidone and electron-rich $p$-terphenyl, and TFA was used to decrease the reactivity of piperidone [60]. It was found that PTP exhibited limited solubility in most polar solvents available, such as NMP, DMSO, N,N-dimethylacetamide (DMAc), and N,N-dimethylformamide (DMF), probably due to its rigid structure, as pre- viously discussed by Olsson et al. [49]. However, in the protonated and quaternized form, PTP displayed good solubility in DMSO and NMP. To use PTP to prepare AEMs and investigate the influence of the side-chain structure on the properties of membranes, three PTP-based AEMs were prepared via the Menshutkin reaction (Fig. 1). Herein, the alkyl halide reagents were added in large excess to facilitate high degrees of conversion. Fig. 1 and Fig. S1 show the photographs and surface scanning electron microscopy (SEM) images of membranes grafted with different side-chain groups. All membranes appeared uniform, homogeneous, and transparent with brown or yellow color. The SEM images show the microstructure of the side-chain groups-grafted PTP membranes, revealing uniform and nonporous structures.

Although pure PTP showed insufficient organo-solubility for confirming the structural identity by ${ }^{1} \mathrm{H}$ NMR, it readily dissolved in DMSO in the protonated form. The ${ }^{1} \mathrm{H}-\mathrm{NMR}$ spectrum of protonated PTP (Fig. 2a) shows signals at 7-8 ppm $\left(\mathrm{H}_{\mathrm{a}, \mathrm{b}}\right), \quad 3.23$ and $3.52 \mathrm{ppm}\left(\mathrm{H}_{\mathrm{d}}\right), 2.75 \mathrm{ppm}\left(\mathrm{H}_{\mathrm{e}}\right), 2.29$, and $2.91 \mathrm{ppm}\left(\mathrm{H}_{\mathrm{c}}\right)$, which agree well with previous reports $[49,50,61]$. The splitting of the $\mathrm{H}_{c}$ and $\mathrm{H}_{\mathrm{d}}$ signal peaks in the spectrum could be attributed to the $N$-protonation of the piperidine ring [49]. The ${ }^{1} \mathrm{H}-\mathrm{NMR}$ spectra and peak assignments of PTP-Q1, PTP-Q5, and PTP-QA are shown in Fig. 2b-d, respectively. It can be seen that different NMR spectra of PTP-Q $x$ membranes were observed after the grafting reaction. Taking the spectrum of PTP-QA as an example, the new peaks that appeared at 1.0$2.0 \mathrm{ppm}$ were attributed to the methylene groups in the BPTMA side chain, indicating the successful grafting of BPTMA into PTP.

Acid doping, swelling, mechanical properties, and ion permeability

Fig. 3a depicts the ADC of different membranes after doping in $3 \mathrm{~mol} \mathrm{~L}^{-1} \mathrm{SA}$ solution at RT. The PTP-QA membrane exhibited the highest $\mathrm{ADC}$ of $10.6 \%$, which was nearly 2.7 and 1.4 times that of PTP-Q1 (4.0\%) and PTP-Q5 (7.5\%) membranes, respectively. The high SA absorption capability of the PTP-QA 

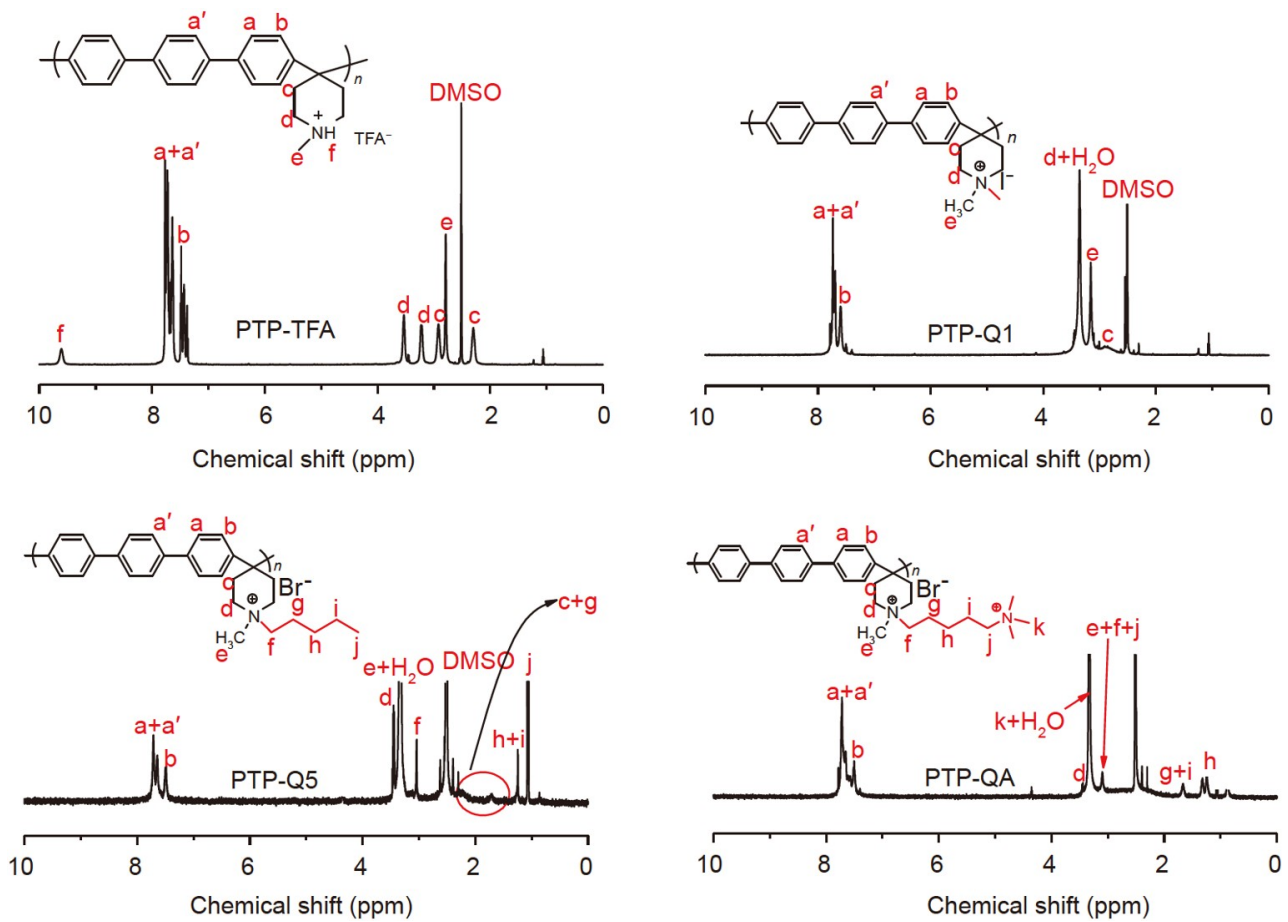

Figure $2{ }^{1} \mathrm{H}-\mathrm{NMR}$ spectra of protonated PTP-TFA, PTP-Q1, PTP-Q5, and PTP-QA and corresponding peak assignments.

membrane apparently results from the grafting of side-chain BPTMA groups, which not only created a larger free volume by disrupting the compact PTP backbone but also increased the hydrophilicity of the membrane by introducing QA end groups. The water uptake results further revealed that the PTP-QA membrane was the most hydrophilic derivative among the membrane chemistries explored. In addition, the PTP-QA polymer contained two anion exchange sites (positively charged), which would absorb more acid (as $\mathrm{HSO}_{4}{ }^{-}$and $\mathrm{SO}_{4}{ }^{2-}$ ) and promote the uptake of excess acid when immersing the PTP-QA membrane in the SA solution [62]. Meanwhile, Fig. 3a shows the VSs of various membranes. The VS increased as the ADC increased. Nevertheless, PTP-Q $x$ membranes exhibited quite low VSs. For example, the PTP-QA membrane displayed a VS of $13.6 \%$, which was much lower than that of the PBI- $42 \%$ EPTMA membrane (ca. 76\%) in our previous work [48].

The mechanical integrity of a membrane is another critical factor for cell assembly and its long-term use in the VRFB. Membranes in VRFBs have to be robust enough to bear the external forces, including the piercing force from carbon fiber electrodes at high compression and the impact from the electrolyte flow [3,5]. As depicted in Fig. 3b, the tensile properties of various SA-doped membranes were recorded. The SA-doped PTP-Q1, PTP-Q5, and PTP-QA membranes displayed similar tensile strengths of around $27 \mathrm{MPa}$. The excellent mechanical stability should result from the rigid polymer backbone of the poly( $p$-terphenyl piperidine). Recently, Bai et al. [61] reported that the pure poly ( $p$-terphenyl piperidine) membrane achieved a high tensile strength of $29 \mathrm{MPa}$ at RT. Meanwhile, the low VS of membranes benefited the mechanical strength, indicating that the grafting of side-chain groups has a minor influence on the tensile properties of SA-doped PTP-Q $x$ membranes.

In pristine AEMs, high selectivity for anions is typically seen in pure water and at low to intermediate degrees of hydration
$[39,41]$. However, when AEMs are immersed in high-ionicstrength solutions, the absorbed excess acid in the AEM matrix can support proton conduction through the AEM [63-65]. The imidazolium-functionalized poly(arylene ether sulfone/ketone) membranes are typical AEMs, which have demonstrated that protons could preferentially transport through the membrane when they are doped with phosphoric acid [66-68]. Another example of the transport of protons through AEMs has been known in diffusion dialysis applications [69,70]. For VRFB containing SA-based electrolytes, ion transport in AEMs is complicated, and both cationic and anionic species can be the charge carriers to balance the redox reactions of the vanadium species. The sulfate anion or other anion in the $\mathrm{H}_{2} \mathrm{SO}_{4}$-based electrolyte is the major charge carrier, whereas the proton can be a minor charge carrier due to the decay of the Donnan exclusion at high ionic strengths $[62,64]$. Although the proton transport in AEM for VRFB has a significant implication, research on the proton transport of AEMs is inadequate. Understanding the proton transport through the positively charged fixed ions of AEMs is beneficial to improving the performance of VRFBs.

The proton $\left(\mathrm{H}^{+}\right)$permeability of various membranes was investigated in a diffusion cell, and the results are depicted in Fig. 3c. Nafion 115 exhibited higher $\mathrm{H}^{+}$permeability $(6.1 \times$ $10^{-5} \mathrm{~cm}^{2} \mathrm{~min}^{-1}$ ) than PTP-Q1 and PTP-Q5 membranes (i.e., $1.8 \times 10^{-5}$ and $\left.1.4 \times 10^{-5} \mathrm{~cm}^{2} \mathrm{~min}^{-1}\right)$. However, the PTP-QA membrane displayed significant $\mathrm{H}^{+}$permeability of $6.7 \times$ $10^{-5} \mathrm{~cm}^{2} \mathrm{~min}^{-1}$, which was even slightly higher than that of Nafion 115. The underlying reason for the high $\mathrm{H}^{+}$permeability of the PTP-QA membrane could be the following two aspects. First, the introduced long side-chain QA group (i.e., BPTMA) increased the hydrophilicity and free volume of the PTP-QA membrane, which in turn favored the crossover of hydrated protons. Second, the absorbed SA molecules in the PTP-QA membrane could benefit the $\mathrm{H}^{+}$transport. Those results implied 

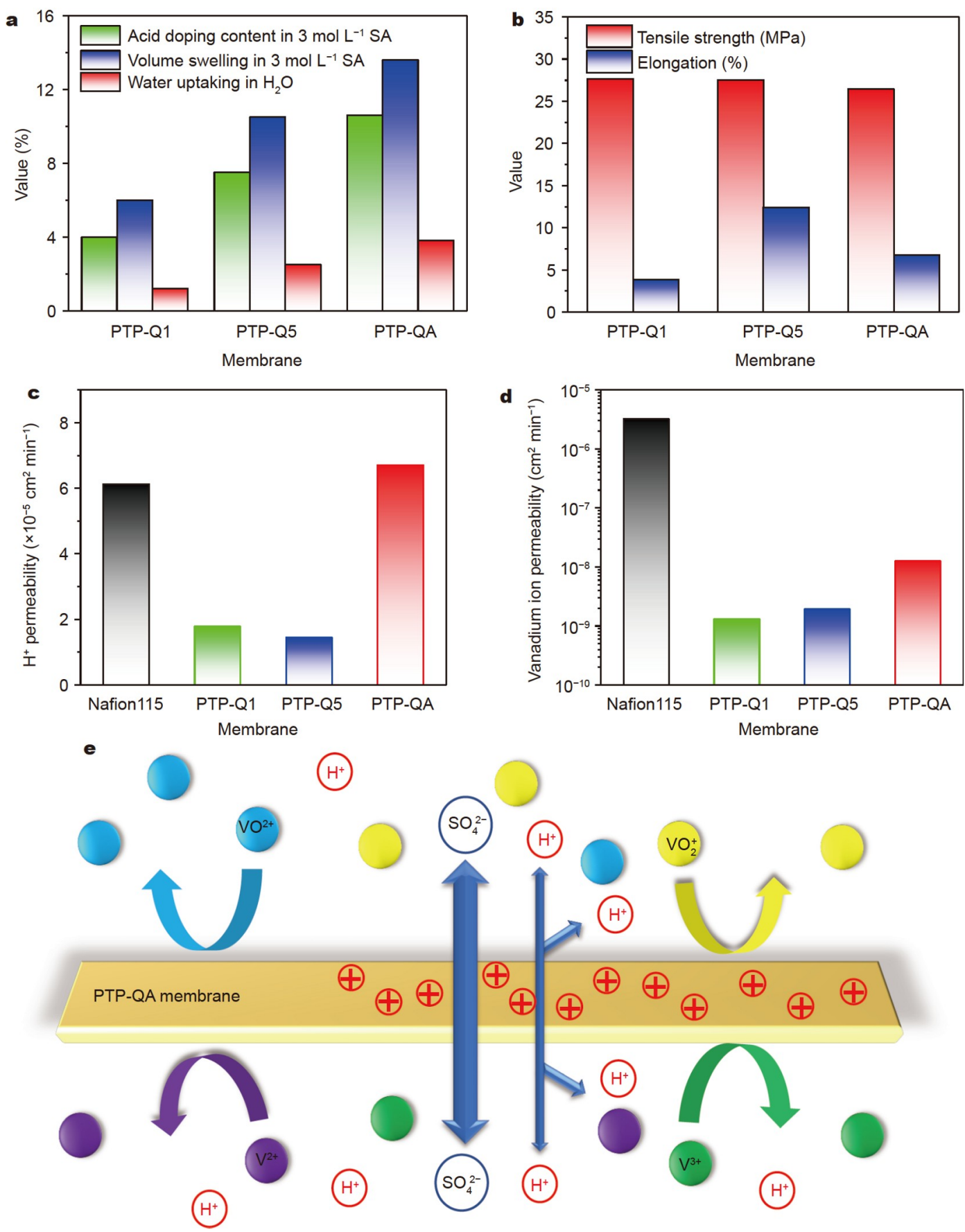

Figure 3 (a) ADC and VS, (b) mechanical properties, (c) $\mathrm{H}^{+}$permeability (pure membranes), (d) vanadium ion permeability (SA-doped membranes after immersing in $3 \mathrm{~mol} \mathrm{~L}^{-1} \mathrm{SA}$ solution at RT) of PTP-Q $x$ membranes and Nafion 115. (e) Illustration of ion transportation through the PTP-Q $x$ AEMs in VRFB.

that AEMs could transport protons when in contact with acidic solutions. Seo et al. [64] observed a similar phenomenon that the pyridine-grafted vinylbenzyl chloride/polyethylene membrane showed high proton transport properties under acidic solutions. Notably, the type and concentration of the testing solution in the diffusion cell should be chosen carefully to overcome the deviation due to the osmotic pressure difference between $3 \mathrm{~mol} \mathrm{~L}^{-1} \mathrm{H}_{2} \mathrm{SO}_{4}$ and testing solutions. As depicted in Fig. $3 \mathrm{c}$ and Fig. S2, the liquid level of the test compartment rose when pure water, saturated $\mathrm{Na}_{2} \mathrm{SO}_{4}$ solution $\left(2.25 \mathrm{~mol} \mathrm{~L}^{-1}\right.$ at $\left.28^{\circ} \mathrm{C}\right)$, and $3 \mathrm{~mol} \mathrm{~L}^{-1} \mathrm{NaCl}$ solution were used, which was obviously due to their higher osmotic pressures than $3 \mathrm{~mol} \mathrm{~L}^{-1} \mathrm{H}_{2} \mathrm{SO}_{4}$ solution. However, the liquid level of the test compartment remained unchanged when $3 \mathrm{~mol} \mathrm{~L}^{-1}$ ammonium sulfate $\left(\left(\mathrm{NH}_{4}\right)_{2} \mathrm{SO}_{4}\right)$ solution was used. Nevertheless, the proton transport in an AEM is complex, and the detailed proton transport mechanism in VRFB using AEMs needs insightful investigations.

The vanadium ion permeability represents the ability of one membrane to prevent the crossover of positive and negative electrolytes in VRFB $[3,5]$. The crossover of vanadium ions across the membrane results in self-discharge (capacity fade) and reduces $\mathrm{CE}$. Therefore, suppressing the crossover of cationic 
vanadium species while promoting proton (or hydrogen sulfate) conduction is the main challenge for membrane developers in this field. Fig. $3 \mathrm{~d}$ shows the vanadium ion $\left(\mathrm{VO}^{2+}\right)$ permeability of various membranes. The $\mathrm{VO}^{2+}$ permeability of the PTP-Q1 and PTP-Q5 membranes, i.e., $1.3 \times 10^{-9}$ and $1.9 \times 10^{-9} \mathrm{~cm}^{2} \mathrm{~min}^{-1}$, respectively, was significantly lower than that of Nafion $(3.3 \times$ $\left.10^{-6} \mathrm{~cm}^{2} \mathrm{~min}^{-1}\right)$. The excellent vanadium ion resistance of those membranes may result from electrostatic repulsion between the cationic piperidinium group in each repeat unit of the polymer main-chain and $\mathrm{VO}^{2+}$ ion, as also observed for other AEM chemistries [6,22,32,38], but nanomorphological effects likely also play a role. For the PTP-QA membrane with two cations of piperidinium and $\mathrm{QA}$ in each polymer repeat unit, it displayed higher $\mathrm{VO}^{2+}$ permeability (i.e., $1.3 \times 10^{-8} \mathrm{~cm}^{2} \mathrm{~min}^{-1}$ ) than PTPQ1 and TPT-Q5. The grafted BPTMA groups had two conflictive influences on the $\mathrm{VO}^{2+}$ permeability. The QA cations of BPTMA groups contribute to electrostatic repulsion of the $\mathrm{VO}^{2+}$ ions, whereas the bulky BPTMA groups contribute to excessive electrolyte uptake and swelling, leading to increased $\mathrm{VO}^{2+}$ permeability. Nevertheless, it was still nearly two orders of magnitude lower than that of Nafion 115, although Nafion 115 exhibited larger thickness (ca. $125 \mu \mathrm{m}$ ). Therefore, it is believed that the PTP-Qx membranes could transport both proton and bisulfate/sulfate ions but retain vanadium ions (Fig. 3e).

\section{ASR, selectivity, and chemical stability}

The ASR of AEM is an essential parameter for electrochemical membrane devices and significantly affects the efficiency of the system. As widely reported, the ASR and conductivity of AEM are connected to the ion exchange capacity (IEC) and mobility of ions; it is also believed that the fixed positive charges on the AEM polymer chain allow for anion transport while restricting the transport of cations by the Donnan exclusion effect $[39,41,45]$. Meanwhile, the intrinsic conductivity of AEMs is lower than that of proton exchange membranes, which primarily results from the low intrinsic mobility of sulfate charge carriers (i.e., $\mathrm{HSO}_{4}{ }^{-}$and $\mathrm{SO}_{4}{ }^{2-}$ ) in the polymer matrix and aqueous electrolyte solution compared with $\mathrm{H}^{+}$mobility $[16,41,64]$. From Fig. $4 \mathrm{a}$, the $\mathrm{H}^{+}$conductivity of Nafion 115 was $47 \mathrm{mS} \mathrm{cm}^{-1}$ at RT, which was nearly three times higher than the $\mathrm{SO}_{4}{ }^{2-}$ conductivity of PTP-Q1 and PTP-Q5 (15 and $17 \mathrm{mS} \mathrm{cm}^{-1}$, measured in deionized water). For the PTP-QA membrane, it achieved an increased $\mathrm{SO}_{4}{ }^{2-}$ conductivity of $37 \mathrm{mS} \mathrm{cm}^{-1}$ compared with PTPQ1 and PTP-Q5, obviously resulting from the presence of two cations in its polymer matrix. From Fig. 4b, the IEC of PTP-QA, as measured by Mohr titration, was $2.80 \mathrm{mmol} \mathrm{g}^{-1}$, which was much higher than those of PTP-Q1 and PTP-Q5 (1.60 and $1.66 \mathrm{mmol} \mathrm{g}^{-1}$, respectively).

For the VRFBs, the SA-based liquid electrolytes were used, and AEMs were immersed in the SA solution. Therefore, the ASR of various AEMs was measured in a $3 \mathrm{~mol} \mathrm{~L}^{-1} \mathrm{H}_{2} \mathrm{SO}_{4}$ solution. For a membrane with a certain conductivity, the ASR depends on the membrane thickness [11,71], so all SA-doped PTP-Q $x$ membranes were cast to a comparable thickness of $55 \mu \mathrm{m}$ in this work. As depicted in Fig. 4c, Nafion 115 displayed an ASR of $0.61 \Omega \mathrm{cm}^{2}$, which agreed with previous results in the literature $[11,48]$. For PTP-Q $x$ membranes, the ASR decreased as the ADC increased. Although PTP-Q1 and PTP-Q5 membranes
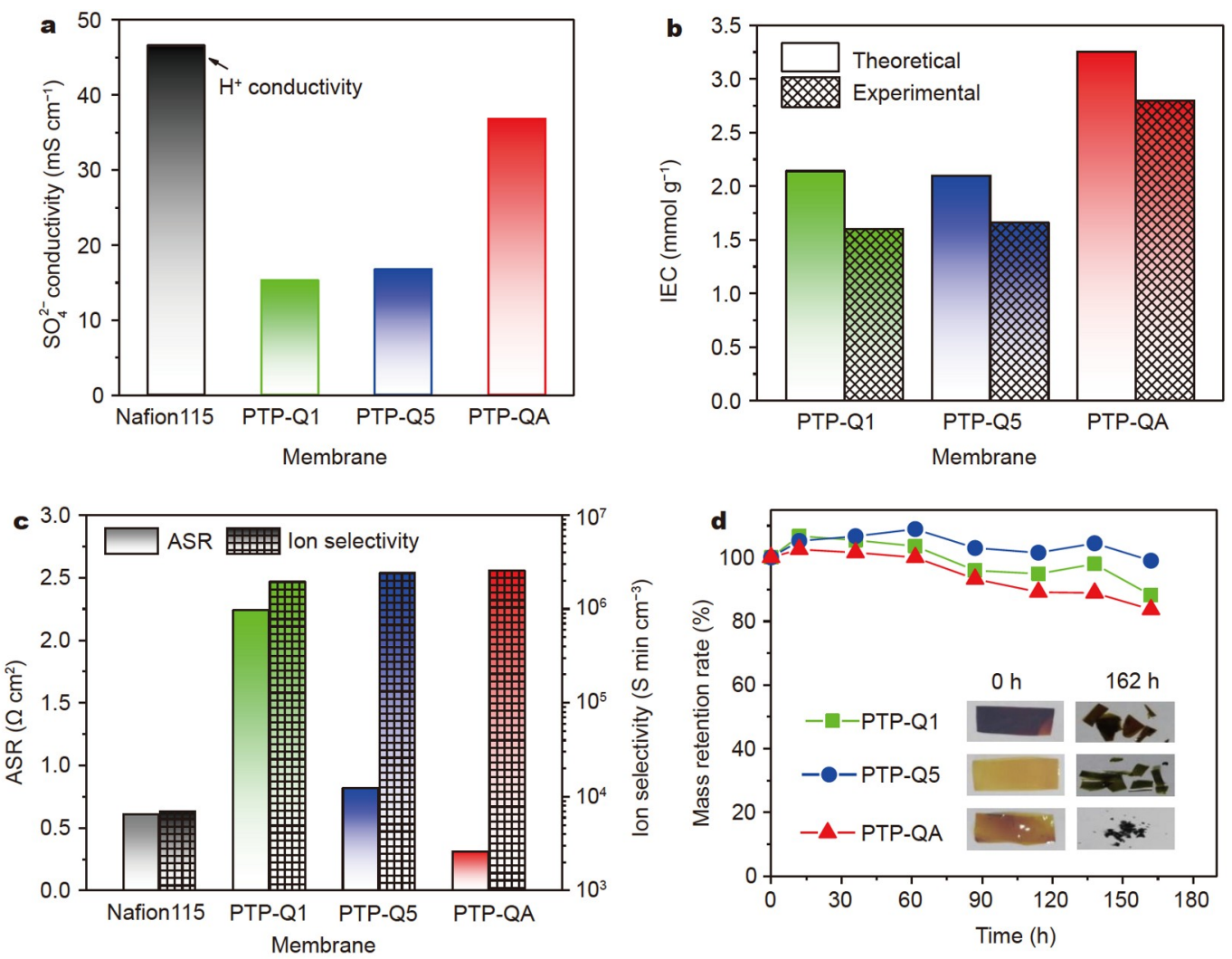

Figure $4 \mathrm{SO}_{4}{ }^{2-}$ conductivity in deionized water (a) and IEC (b) of pristine membranes; ASR and selectivity (c) of various membranes doped in 3 mol $\mathrm{L}^{-1}$ $\mathrm{H}_{2} \mathrm{SO}_{4}$ at RT; (d) chemical stability of various membranes immersed in $1.5 \mathrm{~mol} \mathrm{~L}^{-1} \mathrm{VO}_{2}{ }^{+}$and $3 \mathrm{~mol} \mathrm{~L}^{-1} \mathrm{H}_{2} \mathrm{SO}_{4}$ at $\mathrm{RT}$ as a function of time. Insets show the appearance of membranes before and after the chemical stability test. 
displayed higher ASRs (2.24 and $0.82 \Omega \mathrm{cm}^{2}$ ) than Nafion 115, the PTP-QA membrane achieved the lowest ASR of $0.31 \Omega \mathrm{cm}^{2}$, which was around half value of Nafion 115. The transference number for the different charge carriers remains unknown, but it is likely that the transference number of the negatively charged $\mathrm{HSO}_{4}{ }^{-}$and $\mathrm{SO}_{4}{ }^{2-}$ are significantly higher in the SA-doped PTPQA membrane AEMs than in Nafion. Meanwhile, the existence of protons in the $3 \mathrm{~mol} \mathrm{~L}^{-1} \mathrm{SA}$ solution helped lower the resistance of AEMs. As discussed above, the PTP-QA membrane exhibited a quite high $\mathrm{H}^{+}$permeability. Seo et al. [64] also reported that when an AEM was used in neutral and alkaline solutions, anions carry more than $90 \%$ of charge; moreover, merely $28 \%$ of charge was carried by anions in acidic solutions. Thus, it was deduced that both proton and anion transport mechanisms were available for the PTP-QA membrane in the acidic condition, and the trend was different from the typical ion transfer mechanism of the AEM having a higher anionic selectivity in water. The ASR results revealed that the introduction of a hydrophilic long side-chain QA group was an effective method to decrease the ASR of the SA-doped PTP-Q $x$ membranes. Nevertheless, the ion transport in the AEM is still obscure due to the complicated interaction between different ions [6]; thus, the clear contribution of proton and sulfate ions to the conductivity needs insightful investigations. Compared with ASRs of different AEMs in literature, the PTP-QA membrane had a comparable or lower ASR value. For example, the ASRs of poly(aryl ether ketone) membranes containing QA-grafted 2-adamantane and 3,5-dimethyl phthalazinone (Q2-ADMPEK-4 and QBPPEK80) were 0.35 [27] and $0.58 \Omega \mathrm{cm}^{2}$ [26], respectively; the para-terphenyl-based AEM with QA group-terminated side chain ( $p$ TPN1) exhibited an ASR of around $0.29 \Omega \mathrm{cm}^{2}$ [53]. To comprehensively consider the diffusion ability of charge carriers (i.e., $\mathrm{H}^{+}$and $\mathrm{HSO}_{4}{ }^{-} / \mathrm{SO}_{4}{ }^{2-}$ ) and $\mathrm{VO}^{2+}$ ions through AEMs, the ion selectivity was defined as the ratio of the ionic conductivity to $\mathrm{VO}^{2+}$ permeability $[10,35,72]$. A higher selectivity value means the membrane is more likely to facilitate charge-carrying ions to transfer over the $\mathrm{VO}^{2+}$ ions. From Fig. 4c, the ion selectivity values of PTP-Q1, PTP-Q5, and PTP-QA membranes were

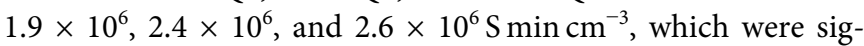

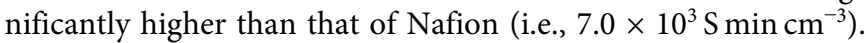
Consequently, the PTP-QA membrane possessed much more optimal ion selectivity, which was nearly 370 times higher than that of Nafion 115, due to the fast transport of charge carriers and low vanadium ion permeability simultaneously.

In addition, the chemical stability of various membranes was examined by immersing membranes in the solution of $1.5 \mathrm{~mol} \mathrm{~L}^{-1} \mathrm{VO}_{2}{ }^{+}$and $3 \mathrm{~mol} \mathrm{~L}^{-1} \mathrm{H}_{2} \mathrm{SO}_{4}$ at RT. The mass retention ratio of PTP-Q1, PTP-Q5, and PTP-QA membranes varied with time (Fig. $4 \mathrm{~d}$ ). The mass of various membranes increased during the first $60 \mathrm{~h}$, which was due to the absorption of $\mathrm{VO}_{2}{ }^{+}$and $\mathrm{H}_{2} \mathrm{SO}_{4}$ [33]. Subsequently, the mass retention ratio began to decline and became $88.1 \%, 99.0 \%$, and $83.7 \%$, respectively, for PTP-Q1, PTP-Q5, and PTP-QA membranes after $162 \mathrm{~h}$. As previously reported, QA AEMs are susceptible to degradation by the attack of high-valence vanadium ions in the highly oxidizing and strongly acidic environment [6,19]. The inset in Fig. 4d shows that PTP-Q1, PTP-Q5, and PTP-QA membranes were broken after $162 \mathrm{~h}$, especially the PTP-QA membrane, which was broken into small pieces, probably because that PTP-QA contained both QA and piperidinium groups in one polymer repeat unit. Therefore, searching for the AEMs with much higher chemical stability should be done in further work.

\section{VRFB performance}

Based on a comprehensive consideration of the various properties of PTP-Q $x$ membranes, the PTP-QA membrane was down-selected for the VRFB tests. As the benchmark, Nafion 115-based VRFB was also assembled and measured. Fig. 5a shows the self-discharge results of VRFBs based on the PTP-QA membrane and Nafion 115. The open-circuit voltages (OCVs) for PTP-QA and Nafion 115 membranes slowly declined to approximately $1.3 \mathrm{~V}$ and then sharply dropped below $0.9 \mathrm{~V}$ as the discharge time increased. Meanwhile, the period of slow voltage decay of the PTP-QA membrane lasted around $130 \mathrm{~h}$, which was about 2.4 times longer than that of Nafion 115 (55 h). The quite low self-discharge ratio of the PTP-QA membrane should be attributed to its low vanadium ion permeability, as discussed above.

The typical charge-discharge curves of VRFBs with PTP-QA and Nafion 115 are plotted at a current density of $100 \mathrm{~mA} \mathrm{~cm}^{-2}$ (Fig. 5b). The PTP-QA membrane displayed a lower charge voltage platform and higher discharge voltage platform than Nafion 115 due to the lower ASR of the PTP-QA membrane. Meanwhile, the charge and discharge capacities of the cell with PTP-QA were much larger than those of Nafion 115, resulting from much lower vanadium ion permeability of the PTP-QA membrane than Nafion $115[27,48]$. Operating the battery at a high current density is beneficial since high working current densities would bring in increased output power densities, allowing for reduced stack sizes and a lower capital cost of the system. Fig. $5 c$, d represent the $\mathrm{CE}, \mathrm{VE}$, and $\mathrm{EE}$ at various charge-discharge current densities between 80 and $160 \mathrm{~mA} \mathrm{~cm}^{-2}$ based on VRFBs equipped with PTP-QA and Nafion 115. As to PTP-QA, the CE maintained nearly unchanged of above $99 \%$ under different current densities due to its low vanadium ion crossover. The VE\% of the battery was reduced as the current density increased, obviously due to the increased ohmic polarization of the battery [26]. Nevertheless, the single-cell based on PTP-QA still displayed a relatively high EE at high current densities, resulting from its low ASR. For example, its EE value reached $81 \%$ at $160 \mathrm{~mA} \mathrm{~cm}^{-2}$, and this value was significantly higher than that of Nafion 115 (68\%) (Fig. 5d). In addition, compared with other AEMs in VRFBs reported in previous studies, the PTP-QA in this work still demonstrates superior EE values (90\% and $89 \%$ ) at 80 and $100 \mathrm{~mA} \mathrm{~cm}^{-2}$ (Fig. 6 and Table S1). In summary, PTP-QA-based cells exhibited excellent battery efficiency performance resulting from a combination of low vanadium ion crossover rate and low ASR.

The stability of the VRFB during long-term operation is an important indicator for measuring the quality of membrane materials. Fig. 7a shows the cycling performance of the PTP-QA membrane and Nafion 115 at $100 \mathrm{~mA} \mathrm{~cm}^{-2}$ and without electrolyte rebalance during the whole cycle. As demonstrated in Fig. 7a, PTP-QA and Nafion 115 were stable and kept almost unchanged CE during all charge-discharged cycles, whereas the VE was slightly lowered, resulting in the decrease in EE. After 156 cycles, the EE of PTP-QA decreased from $91 \%$ to $87 \%$, whereas that of Nafion 115 decreased from $75 \%$ to $71 \%$. The reason for decreased $\mathrm{EE}$ might be due to the incomplete electrochemical reaction of the electrolyte [6]. Moreover, the deposition of $\mathrm{V}_{2} \mathrm{O}_{5}$ would occur, which occupied the reaction sites of the carbon felt, causing the EE and VE decrease [73]. In 

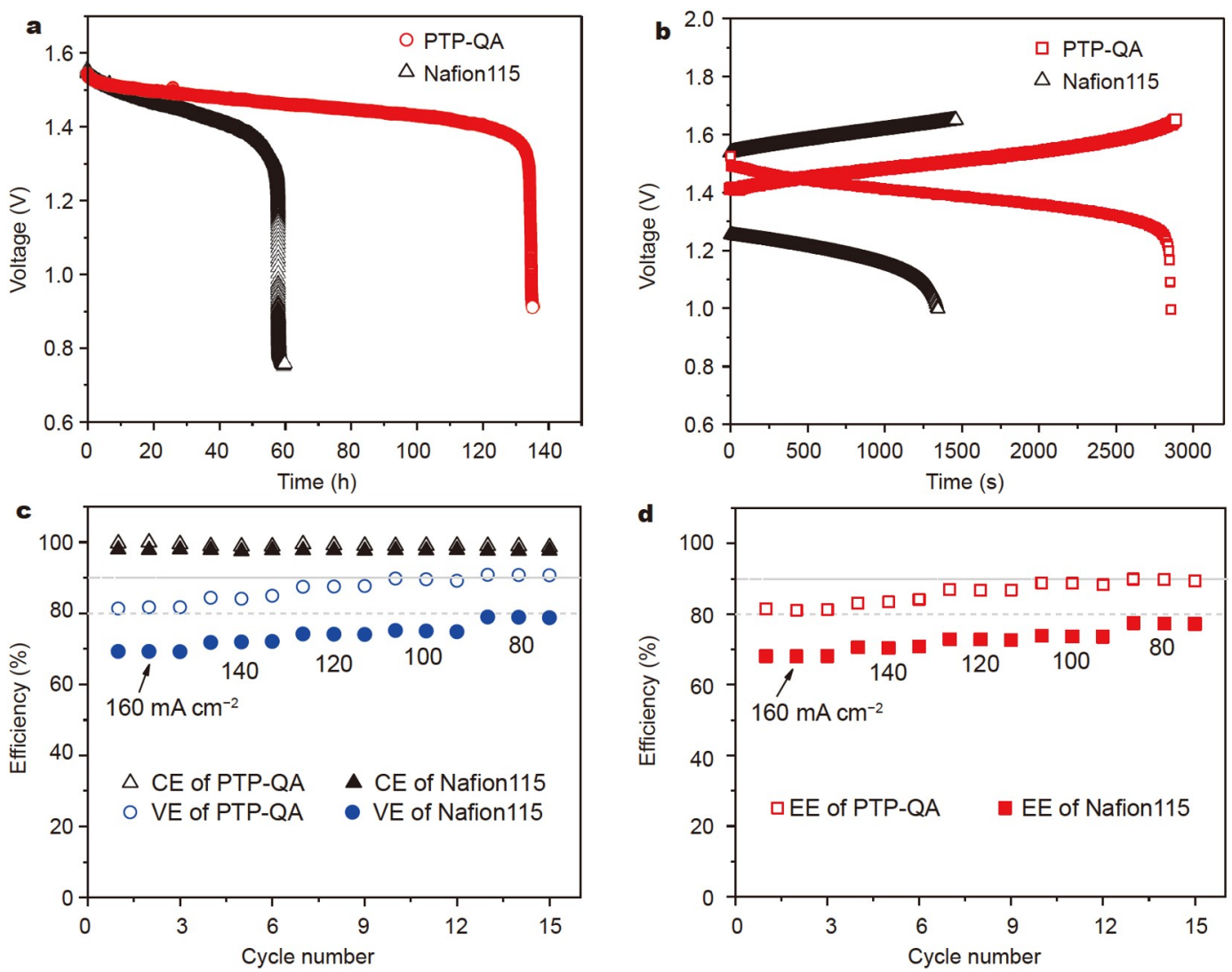

Figure 5 (a) OCV evolution over time, (b) charge-discharge curves at $100 \mathrm{~mA} \mathrm{~cm}^{-2}$, and (c, d) cell performance CE, VE, and EE at different current densities of VRFBs based on PTP-QA and Nafion 115 membranes.

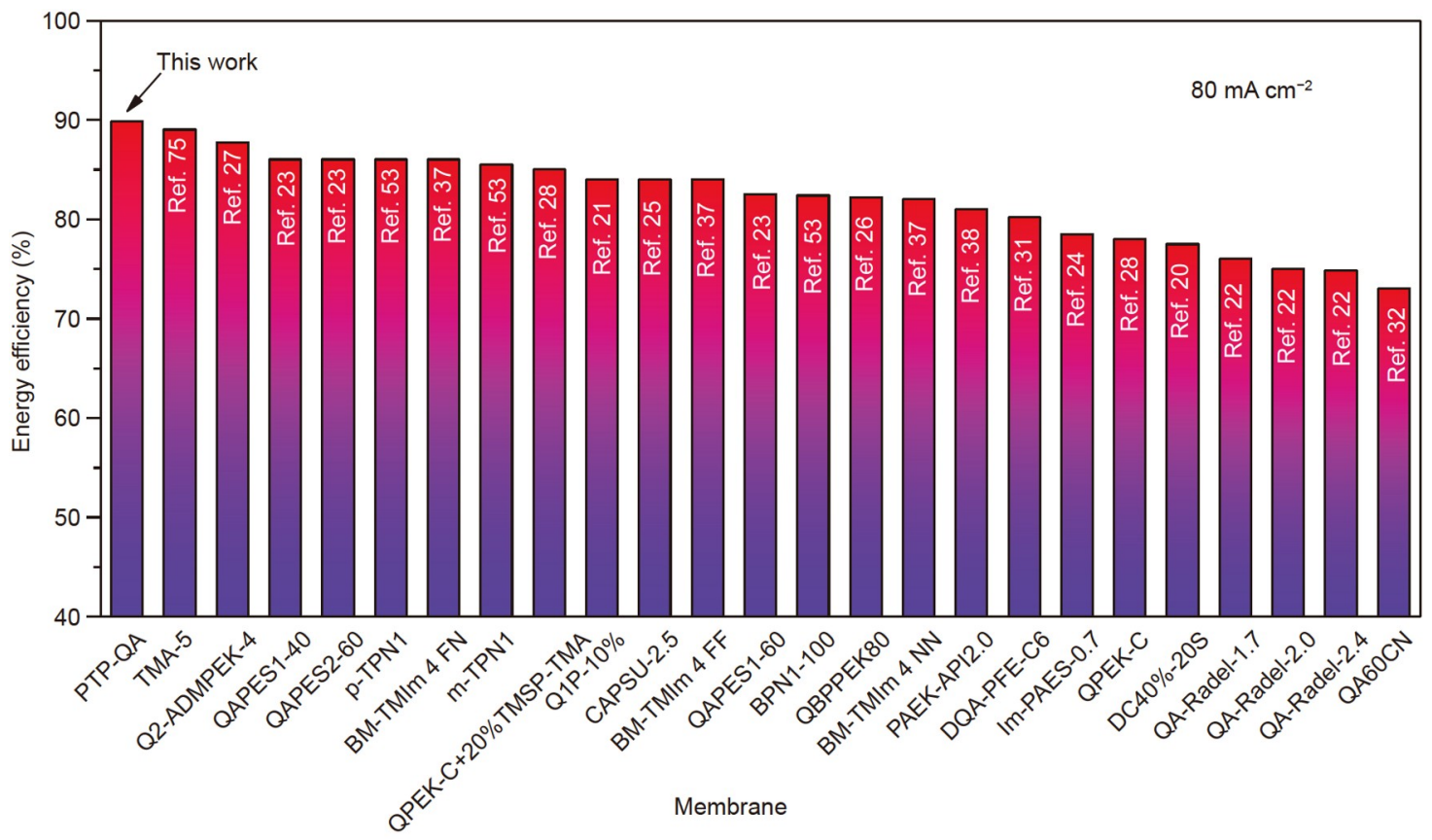

Figure 6 Comparison of the EEs of various AEMs in this work and literature at the current density of $80 \mathrm{~mA} \mathrm{~cm}^{-2}$.

addition, the plastic deformation of the membrane during the charge-discharge process, probably resulting from precipitation and dissolution of vanadium ions in and out of the membrane as well as the swelling and shrinking of membranes in electrolytes, might result in decreased VE and EE as well [74]. Nevertheless, the PTP-QA-based cells exhibited higher CE, VE, and EE than the Nafion 115-based cells during 156 cycles.

Fig. $7 \mathrm{~b}$ depicts the discharge capacity retention of PTP-QA- 

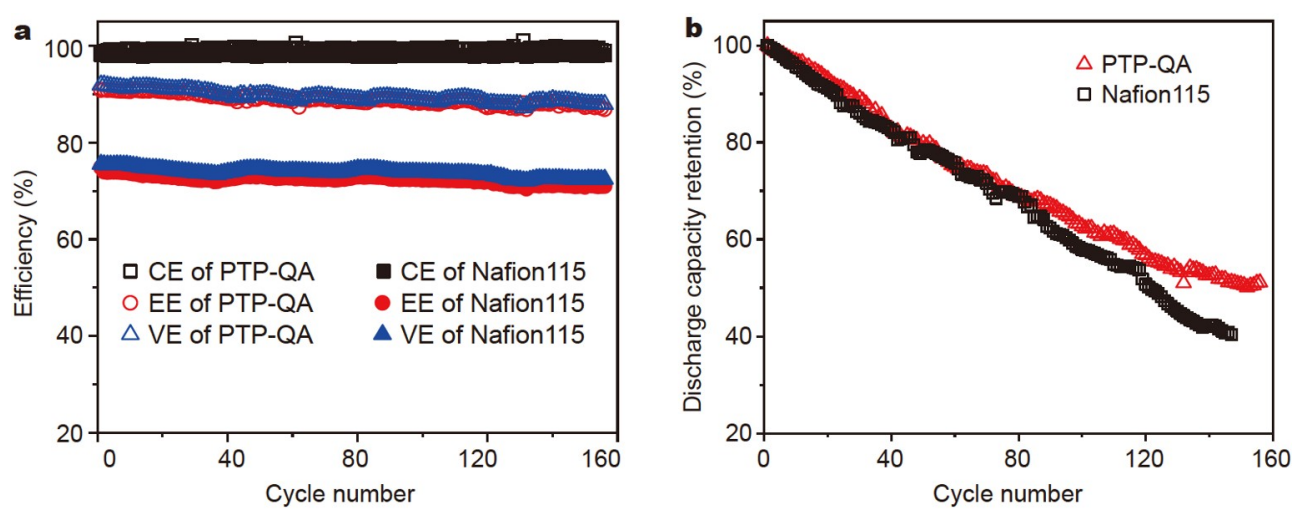

Figure 7 Cycling performance of efficiencies (a) and discharge capacity retention (b) of PTP-QA- and Nafion $115-\mathrm{based}$ VRFBs at $100 \mathrm{~mA} \mathrm{~cm}^{-2}$.

and Nafion 115-based cells. After 156 cycles, the Nafion 115based cells displayed a capacity retention of $40.3 \%$, which was comparable to the results in the literature $[57,75]$. For example, the capacity of the cell with Nafion 115 faded to a value below $46.0 \%$ of the initial value after 100 cycles at a current density of $50 \mathrm{~mA} \mathrm{~cm}^{-2}$ [57]. Zhao et al. [75] showed that the discharge capacity of VRFB equipped with Nafion 115 decayed from $3.0 \mathrm{~A} \mathrm{~h}$ to around $1.1 \mathrm{~A} \mathrm{~h}$ after 150 cycles at $160 \mathrm{~mA} \mathrm{~cm}^{-2}$. Compared with Nafion 115, the cell with PTP-QA exhibited a slightly higher capacity retention of $51.2 \%$ after 156 cycles, which probably resulted from the low vanadium ion permeability of PTP-QA [54]. Nonetheless, the capacity decay rate of PTP-QA was still faster than several high-performance membranes for VRFBs in the recent literature [53,57]. In the longterm operation of VRFB, electrolyte imbalance and electrode side reactions (such as the oxygen and hydrogen evolution reactions at positive and negative electrodes) are the main factors leading to capacity loss $[12,15]$. The asymmetric transfer of various ions and water across membranes would lead to active species imbalance of the electrolyte [6]. Meanwhile, the capacity decay rate of the cell is related to the thickness of the membrane [74]. Although the vanadium ion permeability of PTP-QA was much lower than that of Nafion 115, the thickness of Nafion 115 was around 2.5 times higher than that of PTP-QA. In addition, the $\mathrm{V}(\mathrm{IV})$ ion permeability of membranes was measured as discussed above. In fact, not only V(IV) ions but also V(II, III, $\mathrm{V})$ ions could pass through the membrane. Hence, further optimization, such as the concentration of the electrolyte, electrode composition, and fabrication procedure, needs to be done to improve the discharge capacity retention of the cell. Nevertheless, the PTP-QA membrane can be considered as a potential candidate for VRFBs due to its low area resistance, low vanadium ion crossover, and wide-range structural design.

\section{CONCLUSIONS}

Based on poly(arylene piperidine), a series of poly(arylene piperidinium)-type AEMs were fabricated for VRFBs. The AEMs were optimized by grafting various quaternizing agents with short alkyl (iodomethane), long alkyl (1-bromopentane), and QA group ((5-bromopentyl)-trimethylammonium bromide). ${ }^{1} \mathrm{H}$ NMR confirmed the successful synthesis of poly(arylene piperidinium) polymers. All AEMs exhibited rather lower vanadium permeability than Nafion 115. A method of measuring the $\mathrm{H}^{+}$permeability of the AEM was developed, and the PTP-QA membrane with QA cation-tethered alkyl chain was demonstrated to possess high $\mathrm{H}^{+}$permeability. Owing to both low vanadium ion crossover and high $\mathrm{H}^{+}$permeability, the PTPQA-based AEM displayed 370 times higher ion selectivity than Nafion 115. Meanwhile, the PTP-QA-based AEM exhibited low area resistance of $0.31 \Omega \mathrm{cm}^{2}$ and superior mechanical strength of $26 \mathrm{MPa}$ simultaneously. Consequently, the PTP-QA-based AEM further induced superior VRFB single-cell performance at $80-160 \mathrm{~mA} \mathrm{~cm}^{-2}$. The period of slow voltage decay of the PTPQA-based AEM lasted around $130 \mathrm{~h}$ ( $v s .55 \mathrm{~h}$ for Nafion 115). The VRFB based on PTP-QA-based AEM achieved a high CE of $99 \%$, VE of $91 \%$, and $\mathrm{EE}$ of $90 \%$ at $100 \mathrm{~mA} \mathrm{~cm}^{-2}$. Meanwhile, the VRFB cell performances of PTP-QA AEM had no significant decrease after 156 cycles, and the discharge capacity remained above $50 \%$. This work provides a new guide to design promising AEMs with the high ion-selective and battery performance for VRFB applications.

Received 30 June 2021; accepted 1 September 2021; published online 25 October 2021

1 Soloveichik GL. Flow batteries: Current status and trends. Chem Rev, 2015, 115: 11533-11558

2 Minke C, Turek T. Materials, system designs and modelling approaches in techno-economic assessment of all-vanadium redox flow batteriesA review. J Power Sources, 2018, 376: 66-81

3 Shi Y, Eze C, Xiong B, et al. Recent development of membrane for vanadium redox flow battery applications: A review. Appl Energy, 2019, 238: 202-224

4 Li Z, Lu YC. Material design of aqueous redox flow batteries: Fundamental challenges and mitigation strategies. Adv Mater, 2020, 32: 2002132

5 Prifti H, Parasuraman A, Winardi S, et al. Membranes for redox flow battery applications. Membranes, 2012, 2: 275-306

6 Zeng L, Zhao TS, Wei L, et al. Anion exchange membranes for aqueous acid-based redox flow batteries: Current status and challenges. Appl Energy, 2019, 233-234: 622-643

7 Saal A, Hagemann T, Schubert US. Polymers for battery applicationsActive materials, membranes, and binders. Adv Energy Mater, 2020, 2001984

8 Sun $\mathrm{C}$, Chen J, Zhang $\mathrm{H}$, et al. Investigations on transfer of water and vanadium ions across Nafion membrane in an operating vanadium redox flow battery. J Power Sources, 2010, 195: 890-897

9 Teng X, Dai J, Su J, et al. A high performance polytetrafluoroethene/ Nafion composite membrane for vanadium redox flow battery application. J Power Sources, 2013, 240: 131-139

10 Austing JG, Kirchner CN, Komsiyska L, et al. Layer-by-layer modification of Nafion membranes for increased life-time and efficiency of vanadium/air redox flow batteries. J Membr Sci, 2016, 510: 259-269 
11 Jiang B, Wu L, Yu L, et al. A comparative study of Nafion series membranes for vanadium redox flow batteries. J Membr Sci, 2016, 510: $18-26$

12 Jiang $\mathrm{B}, \mathrm{Yu} \mathrm{L}, \mathrm{Wu} \mathrm{L}$, et al. Insights into the impact of the Nafion membrane pretreatment process on vanadium flow battery performance. ACS Appl Mater Interfaces, 2016, 8: 12228-12238

13 Li Z, Liu L, Yu L, et al. Characterization of sulfonated poly(ether ether ketone)/poly(vinylidene fluoride-co-hexafluoropropylene) composite membrane for vanadium redox flow battery application. J Power Sources, 2014, 272: 427-435

14 Yuan Z, Li X, Hu J, et al. Degradation mechanism of sulfonated poly(ether ether ketone) (SPEEK) ion exchange membranes under vanadium flow battery medium. Phys Chem Chem Phys, 2014, 16: 19841-19847

$15 \mathrm{Yu}$ L, Lin F, Xiao W, et al. Achieving efficient and inexpensive vanadium flow battery by combining $\mathrm{Ce}_{x} \mathrm{Zr}_{1-x} \mathrm{O}_{2}$ electrocatalyst and hydrocarbon membrane. Chem Eng J, 2019, 356: 622-631

16 Skyllas-Kazacos M, Kazacos M. State of charge monitoring methods for vanadium redox flow battery control. J Power Sources, 2011, 196: 88228827

17 Shin DW, Guiver MD, Lee YM. Hydrocarbon-based polymer electrolyte membranes: Importance of morphology on ion transport and membrane stability. Chem Rev, 2017, 117: 4759-4805

18 Chen D, Hickner MA. V ${ }^{5+}$ degradation of sulfonated Radel membranes for vanadium redox flow batteries. Phys Chem Chem Phys, 2013, 15: $11299-11305$

19 Jung MSJ, Parrondo J, Arges CG, et al. Polysulfone-based anion exchange membranes demonstrate excellent chemical stability and performance for the all-vanadium redox flow battery. J Mater Chem A, 2013, 1: 10458-10464

20 Zhang D, Yan X, He G, et al. An integrally thin skinned asymmetric architecture design for advanced anion exchange membranes for vanadium flow batteries. J Mater Chem A, 2015, 3: 16948-16952

21 Ren J, Dong Y, Dai J, et al. A novel chloromethylated/quaternized poly(sulfone)/poly(vinylidene fluoride) anion exchange membrane with ultra-low vanadium permeability for all vanadium redox flow battery. J Membr Sci, 2017, 544: 186-194

22 Chen D, Hickner MA, Agar E, et al. Optimized anion exchange membranes for vanadium redox flow batteries. ACS Appl Mater Interfaces, 2013, 5: 7559-7566

23 Mai Z, Zhang $\mathrm{H}$, Zhang $\mathrm{H}$, et al. Anion-conductive membranes with ultralow vanadium permeability and excellent performance in vanadium flow batteries. ChemSusChem, 2013, 6: 328-335

24 Lu D, Wen L, Nie F, et al. Synthesis and investigation of imidazolium functionalized poly(arylene ether sulfone)s as anion exchange membranes for all-vanadium redox flow batteries. RSC Adv, 2016, 6: 60296037

25 Cha MS, Jeong HY, Shin HY, et al. Crosslinked anion exchange membranes with primary diamine-based crosslinkers for vanadium redox flow battery application. J Power Sources, 2017, 363: 78-86

26 Zhang S, Zhang B, Zhao G, et al. Anion exchange membranes from brominated poly(aryl ether ketone) containing 3,5-dimethyl phthalazinone moieties for vanadium redox flow batteries. J Mater Chem A, 2014, 2: 3083-3091

27 Zhang B, Wang Q, Guan S, et al. High performance membranes based on new 2-adamantane containing poly(aryl ether ketone) for vanadium redox flow battery applications. J Power Sources, 2018, 399: 18-25

28 Yun S, Parrondo J, Ramani V. Composite anion exchange membranes based on quaternized cardo-poly(etherketone) and quaternized inorganic fillers for vanadium redox flow battery applications. Int J Hydrogen Energy, 2016, 41: 10766-10775

29 Chen D, Hickner MA, Agar E, et al. Selective anion exchange membranes for high Coulombic efficiency vanadium redox flow batteries. Electrochem Commun, 2013, 26: 37-40

30 Chen $\mathrm{Y}$, Lin $\mathrm{Q}$, Zheng Y, et al. Densely quaternized anion exchange membranes synthesized from Ullmann coupling extension of ionic segments for vanadium redox flow batteries. Sci China Mater, 2019, 62: 211-224

31 Chen Y, Li Y, Wang B, et al. Fluorinated poly(fluorenyl ether)s with linear multi-cationic side chains for vanadium redox flow batteries. Sci China Mater, 2021, 64: 349-361

32 Park EJ, Maurya S, Martinez U, et al. Quaternized poly(arylene ether benzonitrile) membranes for vanadium redox flow batteries. J Membr Sci, 2021, 617: 118565

33 Fang J, Xu H, Wei X, et al. Preparation and characterization of quaternized poly (2,2,2-trifluoroethyl methacrylate-co- $N$-vinylimidazole) membrane for vanadium redox flow battery. Polym Adv Technol, 2013, 24: $168-173$

34 Hwang CW, Park HM, Oh CM, et al. Synthesis and characterization of vinylimidazole-co-trifluoroethylmethacrylate-co-divinylbenzene anionexchange membrane for all-vanadium redox flow battery. J Membr Sci, 2014, 468: 98-106

35 Roh SH, Lim MH, Sadhasivam T, et al. Investigation on physico-chemical and electrochemical performance of poly(phenylene oxide)-based anion exchange membrane for vanadium redox flow battery systems. Electrochim Acta, 2019, 325: 134944

36 Chu F, Chu X, Lv T, et al. Amphoteric membranes based on sulfonated polyether ether ketone and imidazolium-functionalized polyphenylene oxide for vanadium redox flow battery applications. ChemElectroChem, 2019, 6: 5041-5050

37 Cho H, Krieg HM, Kerres JA. Performances of anion-exchange blend membranes on vanadium redox flow batteries. Membranes, 2019, 9: 31

38 Ahn Y, Kim D. Anion exchange membrane prepared from imidazolium grafted poly(arylene ether ketone) with enhanced durability for vanadium redox flow battery. J Ind Eng Chem, 2019, 71: 361-368

39 Maurya S, Shin SH, Kim Y, et al. A review on recent developments of anion exchange membranes for fuel cells and redox flow batteries. RSC Adv, 2015, 5: 37206-37230

40 Yuan Z, Li X, Zhao Y, et al. Mechanism of polysulfone-based anion exchange membranes degradation in vanadium flow battery. ACS Appl Mater Interfaces, 2015, 7: 19446-19454

41 Merle G, Wessling M, Nijmeijer K. Anion exchange membranes for alkaline fuel cells: A review. J Membr Sci, 2011, 377: 1-35

42 Hwang GJ, Kim SW, In DM, et al. Application of the commercial ion exchange membranes in the all-vanadium redox flow battery. J Ind Eng Chem, 2018, 60: 360-365

43 Shen W, Fu X, Yao T. Physical Chemistry (fifth ed., Volume II) (in Chinese), vol. 1, Beijing: Higher Education Press, 2006.

44 Park EJ, Kim YS. Quaternized aryl ether-free polyaromatics for alkaline membrane fuel cells: Synthesis, properties, and performance-A topical review. J Mater Chem A, 2018, 6: 15456-15477

45 Li H, Kraglund MR, Reumert AK, et al. Poly(vinyl benzyl methylpyrrolidinium) hydroxide derived anion exchange membranes for water electrolysis. J Mater Chem A, 2019, 7: 17914-17922

46 Abdiani M, Abouzari-Lotf E, Ting TM, et al. Novel polyolefin based alkaline polymer electrolyte membrane for vanadium redox flow batteries. J Power Sources, 2019, 424: 245-253

47 Lee Y, Kim S, Maljusch A, et al. Polybenzimidazole membranes functionalised with 1-methyl-2-mesitylbenzimidazolium ions via a hexyl linker for use in vanadium flow batteries. Polymer, 2019, 174: 210-217

48 Ren X, Zhao L, Che X, et al. Quaternary ammonium groups grafted polybenzimidazole membranes for vanadium redox flow battery applications. J Power Sources, 2020, 457: 228037

49 Olsson JS, Pham TH, Jannasch P. Poly(arylene piperidinium) hydroxide ion exchange membranes: Synthesis, alkaline stability, and conductivity. Adv Funct Mater, 2018, 28: 1702758

50 Peng H, Li Q, Hu M, et al. Alkaline polymer electrolyte fuel cells stably working at $80^{\circ} \mathrm{C}$. J Power Sources, 2018, 390: 165-167

51 Wang J, Zhao Y, Setzler BP, et al. Poly(aryl piperidinium) membranes and ionomers for hydroxide exchange membrane fuel cells. Nat Energy, 2019, 4: 392-398

52 Noh S, Jeon JY, Adhikari S, et al. Molecular engineering of hydroxide conducting polymers for anion exchange membranes in electrochemical energy conversion technology. Acc Chem Res, 2019, 52: 27452755

53 Wang T, Jeon JY, Han J, et al. Poly(terphenylene) anion exchange membranes with high conductivity and low vanadium permeability for vanadium redox flow batteries (VRFBs). J Membr Sci, 2020, 598: 


\section{5}

54 Yan X, Zhang H, Hu Z, et al. Amphoteric-side-chain-functionalized "ether-free" poly(arylene piperidinium) membrane for advanced redox flow battery. ACS Appl Mater Interfaces, 2019, 11: 44315-44324

55 Yang J, Che Q, Zhou L, et al. Studies of a high temperature proton exchange membrane based on incorporating an ionic liquid cation 1butyl-3-methylimidazolium into a Nafion matrix. Electrochim Acta, 2011, 56: 5940-5946

56 Klumpp DA, Garza M, Jones A, et al. Synthesis of aryl-substituted piperidines by superacid activation of piperidones. J Org Chem, 1999, 64: 6702-6705

57 Jang JK, Kim TH, Yoon SJ, et al. Highly proton conductive, dense polybenzimidazole membranes with low permeability to vanadium and enhanced $\mathrm{H}_{2} \mathrm{SO}_{4}$ absorption capability for use in vanadium redox flow batteries. J Mater Chem A, 2016, 4: 14342-14355

58 Jung $\mathrm{M}$, Lee $\mathrm{W}$, Noh $\mathrm{C}$, et al. Blending polybenzimidazole with an anion exchange polymer increases the efficiency of vanadium redox flow batteries. J Membr Sci, 2019, 580: 110-116

59 Che X, Zhao H, Ren X, et al. Porous polybenzimidazole membranes with high ion selectivity for the vanadium redox flow battery. J Membr Sci, 2020, 611: 118359

60 Guzmán-Gutiérrez MT, Nieto DR, Fomine S, et al. Dramatic enhancement of superacid-catalyzed polyhydroxyalkylation reactions. Macromolecules, 2011, 44: 194-202

61 Bai H, Peng H, Xiang Y, et al. Poly(arylene piperidine)s with phosphoric acid doping as high temperature polymer electrolyte membrane for durable, high-performance fuel cells. J Power Sources, 2019, 443: 227219

62 Ye R, Henkensmeier D, Yoon SJ, et al. Redox flow batteries for energy storage: A technology review. J Electrochem En Conv Stor, 2018, 15: 010801

63 Kimura N, Matsumoto H, Konosu Y, et al. Membrane potential across anion-exchange membranes in acidic solution system. J Colloid Interface Sci, 2005, 286: 288-293

64 Seo SJ, Kim BC, Sung KW, et al. Electrochemical properties of porefilled anion exchange membranes and their ionic transport phenomena for vanadium redox flow battery applications. J Membr Sci, 2013, 428: $17-23$

65 Münchinger A, Kreuer KD. Selective ion transport through hydrated cation and anion exchange membranes I. The effect of specific interactions. J Membr Sci, 2019, 592: 117372

66 Yang J, Li Q, Jensen JO, et al. Phosphoric acid doped imidazolium polysulfone membranes for high temperature proton exchange membrane fuel cells. J Power Sources, 2012, 205: 114-121

67 Yang J, Wang J, Liu C, et al. Influences of the structure of imidazolium pendants on the properties of polysulfone-based high temperature proton conducting membranes. J Membr Sci, 2015, 493: 80-87

68 Yang J, Wang Y, Yang G, et al. New anhydrous proton exchange membranes based on fluoropolymers blend imidazolium poly(aromatic ether ketone)s for high temperature polymer electrolyte fuel cells. Int J Hydrogen Energy, 2018, 43: 8464-8473

69 Lorrain Y, Pourcelly G, Gavach C. Influence of cations on the proton leakage through anion-exchange membranes. J Membr Sci, 1996, 110: 181-190

70 Luo J, Wu C, Xu T, et al. Diffusion dialysis-concept, principle and applications. J Membr Sci, 2011, 366: 1-16

71 Noh C, Jung M, Henkensmeier D, et al. Vanadium redox flow batteries using meta-polybenzimidazole-based membranes of different thicknesses. ACS Appl Mater Interfaces, 2017, 9: 36799-36809

72 Chae IS, Luo T, Moon GH, et al. Ultra-high proton/vanadium selectivity for hydrophobic polymer membranes with intrinsic nanopores for redox flow battery. Adv Energy Mater, 2016, 6: 1600517

73 Liu Y, Yu L, Liu L, et al. Tailoring the vanadium/proton ratio of electrolytes to boost efficiency and stability of vanadium flow batteries over a wide temperature range. Appl Energy, 2021, 301: 117454

74 Xing Y, Geng $\mathrm{K}$, Chu X, et al. Chemically stable anion exchange membranes based on $\mathrm{C} 2$-protected imidazolium cations for vanadium flow battery. J Membr Sci, 2021, 618: 118696

75 Zhao Y, Zhang H, Xiao C, et al. Highly selective charged porous membranes with improved ion conductivity. Nano Energy, 2018, 48: 353-360

Acknowledgements This work was supported by the National Natural Science Foundation of China (51603031), the Fundamental Research Funds for the Central Universities of China (N2005026), Liaoning Provincial Natural Science Foundation of China (20180550871 and 2020-MS-087), and the Innovation Fund Denmark (DanFlow). The authors thank Prof. Jianguo Liu of the Chinese Academy of Sciences for the valuable assistance in the vanadium redox flow battery testing.

Author contributions Yang J and Che X designed the experiments; Che X, Tang W, and Dong J performed the experiments; Yang J, Che X, and Aili D wrote the paper. All authors contributed to the interpretation of data and scientific discussion.

Conflict of interest The authors declare that they have no conflict of interest.

Supplementary information Experimental details and supporting data are available in the online version of the paper.

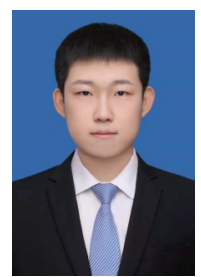

Xuefu Che is currently a master's student at the Department of Chemistry, College of Sciences, Northeastern University (NEU), China. His research interest focuses on the synthesis of new polymers for high-temperature proton exchange membrane fuel cells and vanadium redox flow batteries.

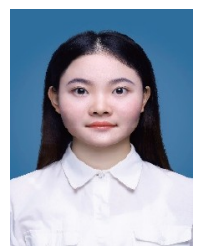

Weiqin Tang is currently a master's student at the Department of Chemistry, College of Sciences, NEU, China Her research interest focuses on the preparation and performance of basic groups functionalized membranes for the vanadium redox flow battery.

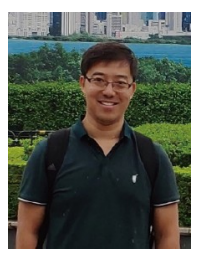

Jingshuai Yang is an associate professor at NEU in China He received his BS degree in applied chemistry and $\mathrm{PhD}$ degree in physical chemistry from NEU in 2007 and 2013, respectively. From 2010 to 2012, he studied at the Technical University of Denmark as a guest PhD. His fields of research include polymer electrolyte membranes and their applications in electrochemical systems (fuel cell, flow battery, water electrolyzer, supercapacitor, et al.). 


\section{长侧链季铵基团功能化聚(亚芳基-哌啶鈆盐)阴离子 交换膜的制备及在全钥液流电池中的应用}

车雪夫 ${ }^{1 \dagger}$, 唐维琴 $^{1 \dagger}$, 董建豪 ${ }^{1}$, David Aili $^{2}$, 杨景帅 ${ }^{1 *}$

摘要 离子选择性是全钒氧化还原液流电池(VRFBs)用膜材料的重要 性能指标. 本文以主链中没有醚键的聚(亚芳基哌啶一哌啶)(PTP)为基体 材料，通过其和硒甲烷、1-澳戊烷和 (5-溴戊基)-三甲基澳化铵间的门 秀金(Menshutkin)反应, 使PTP中哌啶基团季铵化, 合成了不同侧链接 枝的聚(亚芳基-哌啶鍮盐)型阴离子交换膜(AEMs). 研究了AEMs的硫 酸掺杂含量、溶胀性、钥离子渗透性、离子选择性、面电阻、机械性 能、全钥液流电池性能和循环寿命. 同时提出了一种测量AEMs 氢离子 透过率的方法, 结果表明, 氢离子在AEMs中也能有效传导. 长侧链季铵 盐接枝的膜材料(PTP-QA) 具有最高的 $\mathrm{H}^{+}$透过率, 同时具有较低的面电 阻和良好的阻钒性能. PTP-QA膜的离子选择性(电导率与钒离子透过 率的比值) 是Nafion 115离子选择性的 370 倍. 由PTP-QA膜组装的 VRFB，在 $80-160 \mathrm{~m} \mathrm{~A} \mathrm{~cm}^{-2}$ 电流密度下的库伦效率高于 $99 \%$; 在 $100 \mathrm{~mA} \mathrm{~cm}^{-2}$ 下的能量效率高达 $89.8 \%$ (Nafion 115组装的VRFB的能量 效率为 $73.6 \%$ ); 同时, 该VRFB也表现出良好的循环稳定性和容量保持 率. 研究表明聚(亚芳基-哌啶鍮盐)型AEMs 在VRFB中具有潜在的应用 价值. 